\title{
Clinical practice guidelines for the care and treatment of breast cancer: 15 . Treatment for women with stage III or locally advanced breast cancer
}

\author{
Tamara Shenkier, Lorna Weir, Mark Levine, Ivo Olivotto, Timothy Whelan, Leonard Reyno, \\ for the Steering Committee on Clinical Practice Guidelines for the Care and Treatment \\ of Breast Cancer
}

A patient version of these guidelines appears in Appendix 1.

\section{Abstract}

Objective: To define the optimal treatment for women with stage III or locally advanced breast cancer (LABC).

Evidence: Systematic review of English-language literature retrieved from MEDLINE (1984 to June 2002) and CANCERLIT (1983 to June 2002). A nonsystematic review of the literature was continued through December 2003.

Recommendations:

- The management of LABC requires a combined modality treatment approach involving surgery, radiotherapy and systemic therapy.

Systemic therapy: chemotherapy

Operable tumours

- Patients with operable stage IIIA disease should be offered chemotherapy. They should receive adjuvant chemotherapy following surgery, or primary chemotherapy followed by locoregional management.

- Chemotherapy should contain an anthracycline. Acceptable regimens are 6 cycles of FAC, CAF, CEF or FEC. Taxanes are under intense investigation.

Inoperable tumours

- Patients with stage IIIB or IIIC disease, including those with inflammatory breast cancer and those with isolated ipsilateral internal mammary or supraclavicular lymph-node involvement, should be treated with primary anthracycline-based chemotherapy.

- Acceptable chemotherapy regimens are FAC, CAF, CEF or FEC. Taxanes are under intense investigation.

- Patients with stage IIIB or IIIC disease who respond to primary chemotherapy should be treated until the response plateaus or to a maximum of 6 cycles (minimum 4 cycles). Patients with stage IIIB disease should then undergo definitive surgery and irradiation. The locoregional management of patients with stage IIIC disease who respond to chemotherapy should be individualized. In patients with stage IIIB or IIIC disease who achieve maximum response with fewer than 6 cycles, further adjuvant chemotherapy can be given following surgery and irradiation. Patients whose tumours do not respond to primary chemotherapy can be treated with taxane chemotherapy or can proceed directly to irradiation followed by modified radical mastectomy, if feasible.

Systemic therapy: hormonal therapy

Operable and inoperable tumours

- Tamoxifen for 5 years should be recommended to pre- and postmenopausal women whose tumours are hormone responsive.

Locoregional management

Operable tumours

- Patients with stage IIIA disease should receive both modified radical mastectomy (MRM) and locoregional radiotherapy if feasible. They may be managed with MRM followed by chemotherapy and locoregional radiotherapy, or chemotherapy first followed by MRM and locoregional radiotherapy. Breast-conserving surgery is currently not a standard approach.

- Locoregional radiotherapy should be delivered to the chest wall and to the supraclavicular and axillary nodes. The role of internal mammary irradiation is unclear.

Inoperable tumours

- Patients with stage IIIB disease who respond to chemotherapy should receive surgery plus locoregional radiotherapy.

- The locoregional management of patients with stage IIIC disease who respond to chemotherapy is unclear and should be individualized.

- Patients whose disease remains inoperable following chemotherapy should receive locoregional radiotherapy with subsequent surgery, if feasible.

Validation: The authors' original text was revised by members of the Steering Committee on Clinical Practice Guidelines for the Care and Treatment of Breast Cancer. Subsequently, feedback was provided by 9 oncologists from across Canada. The final document was approved by the steering committee.

Sponsor: The Steering Committee on Clinical Practice Guidelines for the Care and Treatment of Breast Cancer was convened by Health Canada.

Completion date: December 2003.

CMAJ 2004;170(6):983-94 
$\mathrm{L}$ ocally advanced breast cancer (LABC) occurs relatively infrequently, but it poses a significant clinical challenge. LABC refers to large breast tumours ( $>5 \mathrm{~cm}$ in diameter) associated with either skin or chest-wall involvement or with fixed (matted) axillary lymph nodes or with disease spread to the ipsilateral internal mammary or supraclavicular nodes. ${ }^{1}$ Inflammatory breast cancer, which manifests as a red swollen breast, is considered a type of LABC. The TumourNode-Metastasis (TNM) system is used to classify breast cancer into stages (Table 1). ${ }^{1}$ According to this system, LABC is stage III.

During the last 60 years, the management of LABC has evolved considerably. Initially, patients with LABC were treated with radical mastectomy. ${ }^{2}$ Based on the disappointing results of surgery and radiotherapy ${ }^{2-4}$ in patients with LABC, and the early promising results of adjuvant systemic therapy in women with axillary node-positive breast cancer, ${ }^{5,6}$ systemic therapy was subsequently incorporated along with surgery and radiotherapy into the management of patients with LABC, termed "combined modality therapy." Even with such combined modality therapy, the long-term survival rate is approximately $50 \%$ among patients with LABC. ${ }^{7}$ The focus of this guideline is to determine the optimal therapeutic approach for patients who present with LABC.

\begin{tabular}{lccc}
\hline \multicolumn{4}{l}{ Table 1: TNM staging system for breast cancer } \\
\hline Stage & Tumour status* & Node statust & Metastasis status $\neq$ \\
\hline 0 & Tis & $\mathrm{N}_{0}$ & $\mathrm{M}_{0}$ \\
\hline I & $\mathrm{T}_{1}$ & $\mathrm{~N}_{0}$ & $\mathrm{M}_{0}$ \\
\hline IIA & $\mathrm{T}_{0}$ & $\mathrm{~N}_{1}$ & $\mathrm{M}_{0}$ \\
& $\mathrm{~T}_{1}$ & $\mathrm{~N}_{1}$ & $\mathrm{M}_{0}$ \\
IIB & $\mathrm{T}_{2}$ & $\mathrm{~N}_{0}$ & $\mathrm{M}_{0}$ \\
& $\mathrm{~T}_{2}$ & $\mathrm{~N}_{1}$ & $\mathrm{M}_{0}$ \\
IIIA & $\mathrm{T}_{3}$ & $\mathrm{~N}_{0}$ & $\mathrm{M}_{0}$ \\
& $\mathrm{~T}_{0}$ & $\mathrm{~N}_{2}$ & $\mathrm{M}_{0}$ \\
& $\mathrm{~T}_{1}$ & $\mathrm{~N}_{2}$ & $\mathrm{M}_{0}$ \\
& $\mathrm{~T}_{2}$ & $\mathrm{~N}_{2}$ & $\mathrm{M}_{0}$ \\
IIIB & $\mathrm{T}_{3}$ & $\mathrm{~N}_{1}$ & $\mathrm{M}_{0}$ \\
& $\mathrm{~T}_{3}$ & $\mathrm{~N}_{2}$ & $\mathrm{M}_{0}$ \\
IIIC & $\mathrm{T}_{4}$ & $\mathrm{~N}_{0}$ & $\mathrm{M}_{0}$ \\
\hline IV & $\mathrm{T}_{4}$ & $\mathrm{~N}_{1}$ & $\mathrm{M}_{0}$ \\
\hline
\end{tabular}

*Tumour status: Tis = carcinoma in situ; $\mathrm{T}_{0}=$ no evidence of primary tumour; $\mathrm{T}_{1}=$ tumour $\leq 2 \mathrm{~cm}$ in greatest dimension; $\mathrm{T}_{2}=$ tumour $>2 \mathrm{~cm}$ but not $>5 \mathrm{~cm}$ in greatest dimension;

$\mathrm{T}_{3}=$ tumour $>5 \mathrm{~cm}$ in greatest dimension; $\mathrm{T}_{4}=$ tumour of any size with chest-wall extension, ulceration, peau d'orange or inflammatory breast cancer.

†Node status: $\mathrm{N}_{0}=$ no regional lymph-node metastasis; $\mathrm{N}_{1}=$ metastasis in movable ipsilateral axillary lymph node(s); $N_{2}=$ metastases in ipsilateral axillary lymph nodes fixed or matted, or in clinically apparent ipsilateral internal mammary nodes in the absence of clinically evident axillary lymph-node metastasis; $\mathrm{N}_{3}=$ metastasis in ipsilateral internal mammary lymph node(s) or in ipsilateral supraclavicular lymph node(s).

$\neq$ Metastasis status: $M_{0}=$ no distant metastasis; $M_{1}=$ distant metastasis.

\section{Methods}

We conducted a systematic review of the English-language literature retrieved from MEDLINE (1984 to June 2002) and CANCERLIT (1983 to June 2002). Search terms used were "breast neoplasms," "locally advanced breast cancer," "stage III breast cancer," "drug therapy," "neo-adjuvant," "primary systemic therapy," "radiotherapy or irradiation," "surgery," "randomized trials" and "high-dose therapy." A nonsystematic review of the literature was continued through December 2003. Additional data were identified by reviewing references in retrieved reports and by monitoring major conferences on breast cancer. The quality of the evidence on which conclusions are based is categorized into 5 levels. ${ }^{8}$ The main outcomes considered are locoregional control (defined as freedom from recurrence in the breast, chest wall or regional lymph nodes), disease-free survival (DFS; defined as survival free of breast cancer recurrence) and overall survival (OS).

We were faced with a number of challenges when trying to synthesize the results of the studies from the review of the literature. These included:

- Many studies were case series (levels IV and V evidence).

- The studies included different populations of patients with differing prognoses; for example, some studies included patients with inflammatory breast cancer whereas other studies did not.

- In studies evaluating systemic therapies, local therapy (surgery/radiotherapy) was often not standardized.

- The TNM tumour-staging system changed, in that tumours associated with ipsilateral supraclavicular nodal involvement that were initially considered LABC were considered metastatic breast cancer between 1987 and 2002 and are now considered LABC again. ${ }^{1}$

- The randomized trials that were available were old, had small patient numbers and used systemic therapy combinations that are often not used today.

We developed this guideline using a framework based on the operability of the tumour. The current TNM staging system, which is based on clinical characteristics of the primary tumour and regional lymph nodes, is used to help determine operability (Table 1). ${ }^{1}$ Large operable tumours include stage IIB and IIIA disease. Nonoperable tumours include stage IIIB or stage IIIC disease. Patients with ipsilateral supraclavicular lymph-node involvement as their sole site of metastases have in the past been classified as having stage IV breast cancer, but they have a better prognosis than patients with other sites of metastases and are included in the category of inoperable LABC (stage IIIC disease) within this guideline. ${ }^{1,9,10}$

\section{Recommendations (including evidence and rationale)}

- The management of $\mathrm{LABC}$ requires a combined modality treatment approach involving surgery, radiotherapy and systemic therapy.

The clinical management of LABC is complex and should be tailored to the individual patient. Frequently, surgery, radiotherapy and systemic therapy (chemotherapy, hormone therapy) are used. A multidisciplinary approach 
to $\mathrm{LABC}$ is recommended in which treatment is based on the combined opinions of a surgeon, radiation oncologist and medical oncologist. The initial management of LABC requires histological confirmation (e.g., core biopsy, incisional biopsy or skin biopsy) for diagnosis and for determination of hormone receptor and HER-2 neu oncogene status. Cytological evaluation by fine-needle aspiration is insufficient.

\section{Systemic therapy: chemotherapy}

\section{Operable tumours}

- Patients with operable stage IIIA disease should be offered chemotherapy. They should receive adjuvant chemotherapy following surgery, or primary chemotherapy followed by locoregional management.
Patients with stage IIIA breast cancer have potentially operable tumours. There are 2 approaches for treating these patients. The first is modified radical mastectomy (MRM) followed by adjuvant systemic therapy and radiotherapy, and the second is preoperative chemotherapy followed by surgery and radiotherapy.

\section{Surgery followed by adjuvant chemotherapy}

There have been only 2 randomized clinical trials of adjuvant chemotherapy exclusively in patients with stage III disease (Table 2). ${ }^{11,12}$ One of these studies ${ }^{11}$ reported a benefit with chemotherapy (level I evidence). The metaanalysis of the Early Breast Cancer Trialists' Collaborative Group (EBCTCG) ${ }^{5,6}$ included a subset of patients with large operable tumours. Overall, all patients benefited from adjuvant systemic chemotherapy regardless of tumour size (level I evidence). Therefore, it is

Table 2: Summary of studies with surgery followed by adjuvant chemotherapy

\begin{tabular}{|c|c|c|c|c|c|c|}
\hline Study & Patients & $\begin{array}{l}\text { No. of } \\
\text { patients }\end{array}$ & Treatment regimens & $\begin{array}{l}\text { Duration of } \\
\text { follow-up }\end{array}$ & $\begin{array}{l}\text { Level of } \\
\text { evidence }\end{array}$ & Results/comments \\
\hline $\begin{array}{l}\text { Klefstrom et al, } \\
1987^{11}\end{array}$ & $\begin{array}{l}\text { Stage III breast } \\
\text { cancer patients after } \\
\text { modified radical } \\
\text { mastectomy }\end{array}$ & 120 & $\begin{array}{l}\text { 1. Radiotherapy } \\
\text { 2. VAC chemotherapy } \\
\text { 3. Both }\end{array}$ & Minimum $5 \mathrm{yr}$ & I & $\begin{array}{l}\text { DFS better with combined treatment } \\
\text { than with either radiotherapy alone } \\
\text { or VAC alone }(p<0.001) \\
\text { (percentages not reported). OS better } \\
\text { with combined treatment than with } \\
\text { radiotherapy alone }(p<0.001) \text { or } \\
\text { VAC alone }(p<0.01) \text { (percentages } \\
\text { not reported) }\end{array}$ \\
\hline $\begin{array}{l}\text { Derman et al, } \\
1989^{12}\end{array}$ & $\begin{array}{l}\text { Patients with LABC } \\
\text { (55\% had } \\
\text { mastectomy) }\end{array}$ & 231 & $\begin{array}{l}\text { 1. Radiotherapy } \\
\text { 2. Radiotherapy + } \\
\text { low-dose CMF } \\
\text { chemotherapy }\end{array}$ & Median 56 mo & II & $\begin{array}{l}\text { No difference in DFS or OS between } \\
\text { the } 3 \text { groups (percentages and } \\
p \text { values not reported) }\end{array}$ \\
\hline
\end{tabular}

3. Radiotherapy + high-dose CMF chemotherapy

De Placido et al, $1995^{26}$

Casper et al, $1987^{27}$

Olson et al (ECOG trial), $1997^{59}$
Patients with stage II or III breast cancer after mastectomy (78 patients had stage III disease)

Patients with LABC treated by modified radical or radical mastectomy

Patients with LABC
who underwent
mastectomy and
were then treated
with CAFTH
chemotherapy

1. CMF chemotherapy alternating with EV chemotherapy

2. CMF chemotherapy alone

\section{6 mo CAF} chemotherapy + 6 mo CMFVP chemotherapy

2. 12 mo CMFVP chemotherapy

\section{3}

1. Radiotherapy

2. Observation + radiotherapy if locoregional failure
Median 48 mo II

No difference in DFS or OS between the 2 groups (percentages and $p$ values not reported)

Median 24 mo II

Median DFS 23 mo in CAF + CMFVP group, 15 mo in CMFVP group $(p=0.05)$. Median OS $33 \mathrm{mo}$ in CAF + CMFVP group, 18 mo in CMFVP group $(p=0.26$ )

Median $9.1 \mathrm{yr}$

DFS not reported. Median survival $8.3 \mathrm{yr}$ in radiotherapy group, $8.1 \mathrm{yr}$ in observation group $(p=0.94)$. Locoregional recurrence $15 \%$ in radiotherapy group, $24 \%$ in observation group ( $p$ value not reported). Median time to relapse $4.7 \mathrm{yr}$ in radiotherapy group, $5.2 \mathrm{yr}$ in observation group $(p=0.68)$

Note: $\mathrm{ECOG}=$ Eastern Clinical Oncology Group, $\mathrm{LABC}=$ locally advanced breast cancer, $\mathrm{DFS}=$ disease-free survival, $\mathrm{OS}=$ overall survival, $\mathrm{V}=$ vincristine, $\mathrm{A}=$ adriamycin

$\mathrm{C}=$ cyclophosphamide, $\mathrm{M}=$ methotrexate, $\mathrm{F}=5$-fluorouracil, $\mathrm{E}=$ epirubicin, $\mathrm{P}=$ prednisone, $\mathrm{T}=$ tamoxifen, $\mathrm{H}=$ fluoxymesterone. 
reasonable to extrapolate the overall conclusions of the meta-analysis to patients with operable stage IIIA disease.

Primary chemotherapy followed by surgery

A number of case series have reported on preoperative chemotherapy in patients with operable stage IIIA breast cancer (level IV evidence). ${ }^{13-16}$ Table 3 summarizes one retrospective study and the randomized trials that compared preoperative and postoperative chemotherapy. ${ }^{15-25}$ The primary purpose of these studies was to determine whether preoperative chemotherapy, compared with postoperative chemotherapy, improved DFS and OS. These studies involved patients mainly with stage I or stage II disease and included a small proportion of women with tumours greater than $5 \mathrm{~cm}$ in diameter. No difference in DFS and OS was detected between the pre-

Table 3: Summary of studies with primary chemotherapy followed by surgery

\begin{tabular}{|c|c|c|c|c|c|c|}
\hline Study & Patients & $\begin{array}{l}\text { No. of } \\
\text { patients }\end{array}$ & Treatment regimens & $\begin{array}{l}\text { Duration of } \\
\text { follow-up }\end{array}$ & $\begin{array}{l}\text { Level of } \\
\text { evidence }\end{array}$ & Results/comments \\
\hline $\begin{array}{l}\text { Hortobagyi et } \\
\text { al, } 2000^{15,16}\end{array}$ & $\begin{array}{l}\text { Patients with } \\
\text { stage IIIA or IIIB } \\
\text { breast cancer } \\
\text { (28\% with stage } \\
\text { IIIA disease; } 25 \% \\
\text { with } \mathrm{T}_{3} \text { tumour) }\end{array}$ & 174 & $\begin{array}{l}\text { All patients received FAC } \\
\text { induction chemotherapy } \\
\text { then total mastectomy or } \\
\text { radiotherapy or both, } \\
\text { followed by adjuvant FAC } \\
\text { followed by CMF } \\
\text { chemotherapy }\end{array}$ & Median 59 mo & IV & $\begin{array}{l}\text { DFS } 71 \% \text { and OS } 84 \% \text { among } \\
\text { patients with stage IIIA disease. } \\
\text { These rates were superior to those } \\
\text { in historical group at the same } \\
\text { institution who were treated with } \\
\text { local modalities alone (no } \\
\text { percentages or } p \text { values reported). } \\
\text { Total clinical response } 87.4 \% ; \\
\text { clinical complete response } 16.7 \%\end{array}$ \\
\hline $\begin{array}{l}\text { Wolmark et al } \\
\text { (NSABP B-18 } \\
\text { trial), } 2001^{19}\end{array}$ & $\begin{array}{l}\text { Patients with } \\
\text { operable, } \\
\text { palpable breast } \\
\text { cancer ( } 13 \% \text { had } \\
{\text { a } \mathrm{T}_{3} \text { tumour) }}^{\text {tumour }}\end{array}$ & 1523 & $\begin{array}{l}\text { 1. Preoperative AC } \\
\text { chemotherapy } \\
\text { 2. Postoperative AC } \\
\text { chemotherapy }\end{array}$ & Mean $9.5 \mathrm{yr}$ & 1 & $\begin{array}{l}\text { DFS } 55 \% \text { in preoperative group, } \\
53 \% \text { in postoperative group }(p= \\
0.50) . \text { OS } 69 \% \text { in preoperative } \\
\text { group, } 70 \% \text { in postoperative } \\
\text { group ( } p=0.80 \text { ). Clinical } \\
\text { response } 80 \% \text { in preoperative } \\
\text { group; clinical complete response } \\
36 \% \text {; pathologic complete } \\
\text { response } 13 \%\end{array}$ \\
\hline
\end{tabular}

Van der Hage et al (EORTC trial), $2001^{20}$

Patients with primary operable breast cancer ( $9 \%$ had a $\mathrm{T}_{3}$ tumour)

$\begin{array}{ll}\begin{array}{l}\text { Broët et al } \\ \text { (Institut Curie), } \\ 1999^{22}\end{array} & \begin{array}{l}\text { Premenopausal } \\ \text { women with } \mathrm{T}_{2}-\end{array} \\ & \begin{array}{l}\mathrm{T}_{3} \text { breast cancer } \\ \left(27 \% \text { had a } \mathrm{T}_{3}\right. \\ \text { tumour) }\end{array} \\ & \begin{array}{l}\text { Patients with } \\ \text { (Institut }\end{array} \\ \begin{array}{l}\text { Bergonie), } \\ 1999^{23}\end{array} & \begin{array}{l}>3 \mathrm{~cm} \text { in } \\ \text { diameter }(18 \%\end{array} \\ & \text { had a } \mathrm{T}_{3} \text { tumour }\end{array}$

Makris et al, $1998^{25}$

\section{1. Preoperative FEC chemotherapy \\ 2. Postoperative FEC chemotherapy}

Median 56 mo I

DFS $65 \%$ in preoperative group, $70 \%$ in postoperative group $(p=$ $0.27)$. OS $82 \%$ in preoperative group, $84 \%$ in postoperative group $(p=0.38)$. Clinical response $49 \%$ in preoperative group; clinical complete response $7 \%$; pathologic complete response $2 \%$

414

1. Preoperative FAC chemotherapy

2. Postoperative FAC chemotherapy

Median 105 mo

II

DFS not reported. OS $65 \%$ in preoperative group, $60 \%$ in postoperative group ( $p=0.36$ ). Clinical response $82 \%$ in preoperative group; clinical complete response $30 \%$

2721.3 cycles of EVM followed Median $124 \mathrm{mo}$ II by 3 cycles of MiTVd chemotherapy preoperatively

2. 3 cycles of EVM followed by 3 cycles of MiTVd chemotherapy postoperatively

309
1. 8 cycles MiMxM chemotherapy preoperatively
2. 4 cycles MiMxM preoperatively and 4 cycles Mix chemotherapy postoperatively

DFS not reported. No difference in OS (percentages and $p$ value not reported). Clinical complete response $32.8 \%$ in preoperative group

No statistically significant difference in DFS or OS (percentages and $p$ values not reported). Clinical response $83 \%$ in preoperative group only; clinical complete response $22 \%$ 
operative and postoperative chemotherapy groups (level II evidence). Preoperative chemotherapy often caused shrinkage of the tumour and permitted the performance of breast-conserving surgery (BCS) when a mastectomy was originally planned. ${ }^{17-25}$ However, results from 2 trials suggested that patients whose tumours were down-staged so that BCS could be performed when it was not initially planned were at higher risk of local recurrence ${ }^{19}$ and had worse survival. ${ }^{20}$

\section{Choice of chemotherapy}

- Chemotherapy should contain an anthracycline. Acceptable regimens are 6 cycles of FAC, CAF, CEF or FEC (see Box 1). Taxanes are under intense investigation.

There have been relatively few trials specifically involving women with operable stage IIIA breast cancer that

\section{Table 3 continued}

\begin{tabular}{|c|c|c|c|c|c|c|}
\hline Study & Patients & $\begin{array}{c}\text { No. of } \\
\text { patients }\end{array}$ & Treatment regimens & $\begin{array}{l}\text { Duration of } \\
\text { follow-up }\end{array}$ & $\begin{array}{l}\text { Level of } \\
\text { evidence }\end{array}$ & Results/comments \\
\hline $\begin{array}{l}\text { Therasse et al, } \\
2003^{7}\end{array}$ & $\begin{array}{l}\text { Women with } \\
\text { LABC ( } 4 \% \text { had a } \\
\left.\mathrm{T}_{3} \text { tumour }\right)\end{array}$ & 448 & $\begin{array}{l}\text { 1. } 6 \text { mo CEF chemotherapy } \\
\text { 2. } 3 \text { mo high-dose EC } \\
\text { chemotherapy + GCSF }\end{array}$ & Median $5.5 \mathrm{yr}$ & II & $\begin{array}{l}\text { Progression-free survival } 34 \text { mo in } \\
\text { CEF group, } 33.7 \text { mo in EC+GCSF } \\
\text { group ( } p=0.68 \text { ). OS } 53 \% \text { in CEF } \\
\text { group, } 51 \% \text { in EC+GCSF group ( } p= \\
0.94) \text {. Clinical response } 58.9 \% \text { in } \\
\text { CEF group, } 60.8 \% \text { in EC+GCSF } \\
\text { group; clinical complete response } \\
31.3 \% \text { in CEF group, } 26.5 \% \text { in } \\
\text { EC+GCSF group ( } p \text { values not } \\
\text { reported) }\end{array}$ \\
\hline
\end{tabular}

Buzdar et al, $1999^{42}$

Patients with operable breast cancer $(17 \%$ had stage IIIA disease)

\begin{abstract}
Smith et al,
\end{abstract} $2002^{43}$

Bear et al (NSABP B-27 trial), $2003^{45}$

Papaioannou et Patients with al, $1983^{61}$
Patients with $\mathrm{LABC}$ or tumour $\geq 3 \mathrm{~cm}$ in diameter who had clinical response to CVAP neoadjuvant chemotherapy

Women with operable primary breast cancer (45\% had tumour $>4 \mathrm{~cm}$ in diameter)

LABC who had 2 cycles of CAVMF chemotherapy preoperatively and 10 cycles postoperatively
174

1. 4 cycles of paclitaxel

Median 23 mo

II preoperatively

2. 4 cycles of FAC preoperatively

102

1. 4 cycles of docetaxel preoperatively

2. 4 additional cycles of the original CVAP chemotherapy preoperatively

2400

1. 4 cycles of $\mathrm{AC}$ chemotherapy + surgery

2. 4 cycles of AC chemotherapy +4 cycles of docetaxel + surgery

3. 4 cycles of $\mathrm{AC}$ chemotherapy + surgery +4 cycles of docetaxel

205

1. Mastectomy

2. Mastectomy + radiotherapy

Median $3 \mathrm{yr} \quad$ I

I

DFS 94\% in paclitaxel group, 89\% in FAC group $(p=0.44)$. OS not reported. Clinical response $80 \%$ in each group; pathologic complete response $8 \%$ in paclitaxel group, $16 \%$ in FAC group ( $p$ values not reported)

OS improved in docetaxel group (percentages not reported, $p=$ $0.05)$. Clinical response $94 \%$ in docetaxel group, $66 \%$ in CVAP group $(p=0.001)$. Pathologic complete response $34 \%$ in docetaxel group, $16 \%$ in CVAP group $(p=0.04)$

Preliminary Preliminary DFS and OS not reported. Clinical results results complete response $40 \%$ at time of surgery increased to $64 \%$ by addition of docetaxel $(p<0.001)$. Pathologic complete response increased from $13.7 \%$ in combined preoperative AC groups to $26.1 \%$ when docetaxel added preoperatively $(p<0.001)$

DFS not reported. No difference in OS (percentages and $p$ value not reported). Local recurrence 10.5\% in mastectomy only group, $8.3 \%$ in radiotherapy group (difference not statistically significant, $p$ value not reported). Systemic recurrence $10.5 \%$ in mastectomy group, $18.7 \%$ in radiotherapy group (difference not statistically significant, $p$ value not reported)

Note: $\mathrm{LABC}=$ locally advanced breast cancer, DFS = disease-free survival, OS = overall survival, NSABP = National Surgical Adjuvant Breast and Bowel Project, EORTC = European Organization for Research and Treatment of Cancer, $\mathrm{A}=$ adriamycin, $\mathrm{C}=$ cyclophosphamide, $\mathrm{F}=5$-fluorouracil, $\mathrm{E}=$ epirubicin, $\mathrm{V}=$ vincristine, $\mathrm{P}=$ prednisone, $\mathrm{M}=$ methotrexate, $\mathrm{GCSF}=$ granulocyte colony stimulating factor, $\mathrm{Mi}=$ mitomycin $\mathrm{C}, \mathrm{T}=$ thiotepa, $\mathrm{Vd}=$ vindesine, $\mathrm{Mx}=$ mitoxantrone. 
have addressed the issue of the type of chemotherapy to be used. ${ }^{11,26,27}$ The number of patients in these trials was small. Two trials showed improved DFS with anthracyclinebased chemotherapy over no chemotherapy (level I evidence ${ }^{11}$ and over a $\mathrm{CMF}$-vincristine-prednisone regimen (level II evidence). ${ }^{27} \mathrm{~A}$ third trial showed no difference in DFS or OS between CMF and a CMF-epirubicinvincristine regimen (level II evidence) (Table 2). ${ }^{26}$ Hence, recommendations concerning the type of chemotherapy regimens to be used in stage IIIA disease are based on extrapolation from trials in women with metastatic breast cancer and node-positive

breast cancer.

Results of randomized trials involving women with metastatic breast cancer have shown a superior response rate and prolonged DFS with anthracycline-containing chemotherapy regimens than with CMF . ${ }^{28,29}$ Randomized trials have confirmed the superiority of anthracycline-containing regimens such as CEF and $\mathrm{CAF}$ over conventional CMF in women with node-negative and node-positive breast cancer. ${ }^{30-32}$ In contrast, in the $\mathrm{Na}$ tional Surgical Adjuvant Breast and Bowel Project (NSABP) B-15 trial, 4 cycles of AC chemotherapy was equivalent to 6 months of $\mathrm{CMF}^{33}$ In the most recent EBCTCG overview, ${ }^{5}$ there was a statistically significant improvement in survival with anthracyclinebased chemotherapy compared with CMF in early stage breast cancer. Although there are limitations to crossstudy comparisons, it is reasonable to consider that 4 cycles of AC, although equivalent to 6 months of $\mathrm{CMF}^{33}$ is probably inferior to 6 cycles of anthracycline-containing drug regimens such as $\mathrm{FAC},{ }^{16} \mathrm{CAF},{ }^{28,30} \mathrm{CEF}^{32}$ and $\mathrm{FEC} .{ }^{34}$ In women who cannot receive anthracyclines because of underlying cardiac disease, CMF chemotherapy can be considered.

Six cycles of chemotherapy should be administered. This is based on the trials of adjuvant chemotherapy that showed that 6 cycles of CAF or CEF was superior to $6 \mathrm{cy}-$ cles of $\mathrm{CMF}^{30,32}$ and that 6 cycles of FEC was superior to 3 cycles of FEC. ${ }^{35}$

In a multicentre trial, 448 women with $\mathrm{LABC}$ were randomly allocated to receive either CEF, or EC plus GCSF (Table 3). ${ }^{7}$ At a median follow-up of 5.5 years, no difference in survival was detected between the 2 groups (53\% and $51 \%$ respectively; level II evidence).
The role of taxanes in LABC and as preoperative chemotherapy in women with early breast cancer is currently under investigation. Studies involving women with metastatic breast cancer indicate that taxanes can cause significant tumour regression and improvement in symptoms in patients with anthracycline-resistant disease. ${ }^{36,37}$ Taxane-containing regimens have been evaluated in randomized trials involving patients with axillary node-positive breast cancer. Compared with AC, AC followed by paclitaxel was associated with improved DFS in 2 trials $^{38,39}$ and with improved OS in 1 trial. ${ }^{38} \mathrm{~A}$ recent trial suggested that $\mathrm{AC}$ administered every 2 weeks followed by paclitaxel every 2 weeks (dose dense chemotherapy) was associated with improved DFS compared with the usual AC followed by paclitaxel, both administered every 3 weeks. ${ }^{40}$ Another recently reported trial involving women with node-positive breast cancer showed that, compared with FAC, the chemotherapy regimen TAC improved DFS and OS. ${ }^{41}$

In a trial of FAC versus paclitaxel, both administered preoperatively, no difference was detected in clinical or pathologic response rate and DFS (Table 3). ${ }^{42}$ Results from 2 studies suggested that the addition of a taxane sequentially to an anthracyclinebased regimen can improve clinical and pathologic response (Table 3). ${ }^{43-45}$

Currently, there are insufficient data to make definitive recommendations concerning the use of taxane-containing regimens in LABC. However, this is an evolving area of investigation. Management of LABC with systemic therapy remains an area for further research, and randomized studies are needed to identify optimal strategies. Participation in clinical trials is encouraged.

\section{Inoperable tumours}

- Patients with stage IIIB or IIIC disease, including those with inflammatory breast cancer and those with isolated ipsilateral internal mammary or supraclavicular lymph-node involvement, should be treated with primary anthracycline-based chemotherapy.

- Acceptable chemotherapy regimens are FAC, CAF, CEF or FEC. Taxanes are under intense investigation. 
[See the discussion of chemotherapy in the section "operable tumours."] The results of trials of chemotherapy in women with metastatic breast cancer and axillary nodepositive breast cancer have demonstrated the superiority of anthracycline-containing combination chemotherapy over $\mathrm{CMF}^{28-32}$ On the basis of this evidence, when chemotherapy is used for treating stage IIIB or IIIC breast cancer, an anthracycline-containing regimen should be used if there are no contraindications to its use. A regimen of FAC, CAF, CEF or FEC is preferred..$^{16,30,32,34}$ An adequate dose intensity and total dose of anthracycline should be used..$^{34,46}$ CMF chemotherapy can be used in women who cannot receive anthracycline-containing chemotherapy because of underlying heart disease. The role of taxanes is currently under investigation, and no recommendations can be made at present for the incorporation of taxanes in primary chemotherapy for inoperable LABC.

There is currently no evidence to support the use of high-dose chemotherapy with stem cell support for this group of patients, as the randomized trials involving women with metastatic breast cancer and breast cancer with extensive nodal involvement have demonstrated no difference in survival between high-dose chemotherapy and standard-dose chemotherapy (level II evidence). ${ }^{47,48}$

- Patients with stage IIIB or IIIC disease who respond to primary chemotherapy should be treated until the response plateaus or to a maximum of 6 cycles (minimum 4 cycles). Patients with stage IIIB disease should then undergo definitive surgery and irradiation. The locoregional management of patients with stage IIIC disease who respond to chemotherapy should be individualized. In patients with stage IIIB or IIIC disease who achieve maximum response with fewer than 6 cycles, further adjuvant chemotherapy can be given following surgery and irradiation. Patients whose tumours do not respond to primary chemotherapy can be treated with taxane chemotherapy or can proceed directly to irradiation followed by modified radical mastectomy, if feasible.

Patients with stage III disease who are treated with primary chemotherapy need to be followed carefully for evidence of response. Multivariate analyses in several studies $^{17-19,49,50}$ have shown that the primary tumour response is correlated with patient outcome and that patients who have pathological evidence of a complete response following primary therapy have a superior DFS and OS compared with those who do not have such a response (level III evidence). Clinical response is seen in about $80 \%$ of patients who receive primary chemotherapy. To ascertain response, at least 2-3 cycles of chemotherapy should be administered.

The treatment of patients with LABC whose tumours do not respond to anthracycline-containing chemotherapy is unclear. It is reasonable to try taxane chemotherapy $y^{42-45}$ or to proceed directly to locoregional therapy including irradiation and MRM, if possible.

Patients with stage IIIB or IIIC disease who do have a clinical response to primary chemotherapy should receive ongoing treatment until the manifested response clearly plateaus or to a maximum of 6 cycles, whichever comes first. The threshold for anthracycline-associated cardiac toxicity should not be exceeded. The optimal duration of primary chemotherapy is unclear. However, the results of studies involving women with node-positive breast cancer who received adjuvant chemotherapy showed that a regimen of 6 cycles of CMF was superior to that of 3 cycles of $\mathrm{CMF}^{51}$ and that a regimen of 6 cycles of FEC was superior to that of 3 cycles of FEC. ${ }^{35}$

It is unclear whether additional chemotherapy should be administered following primary chemotherapy and definitive locoregional therapy. This has been examined in several case series (level V evidence). ${ }^{15,16,49}$

\section{Systemic therapy: hormonal therapy}

\section{Operable and inoperable tumours}

- Tamoxifen for 5 years should be recommended to pre-and postmenopausal women whose tumours are hormone responsive.

Following completion of chemotherapy, pre- or postmenopausal patients with LABC and hormone-responsive tumours should receive adjuvant tamoxifen therapy, $20 \mathrm{mg} / \mathrm{d}$, for 5 years (see guideline 8), ${ }^{5,52}$ Tamoxifen should be started after completion of chemotherapy. ${ }^{53}$ The aromatase inhibitor, anastrozole, has been compared with tamoxifen in postmenopausal women with early breast cancer following surgery. ${ }^{54}$ The early results of that study showed that, compared with tamoxifen, anastrozole was associated with improved DFS and had fewer side effects. The role of aromatase inhibitors as adjuvant therapy in breast cancer is evolving. ${ }^{55}$ The role of luteinizing hormone-releasing hormone agonists in premenopausal patients is evolving as new data emerge (see guideline 8).

Patients who are not candidates for any chemotherapy can be managed with hormonal treatment and then receive locoregional management as described below. ${ }^{56-58}$

\section{Locoregional management}

\section{Operable tumours}

- Patients with stage IIIA disease should receive both modified radical mastectomy (MRM) and locoregional radiotherapy if feasible. They may be managed with MRM followed by chemotherapy and locoregional radiotherapy, or chemotherapy first followed by MRM and locoregional radiotherapy. Breast-conserving surgery is currently not a standard approach. 
MRM (mastectomy plus a level 1 and level 2 axillary dissection) remains the standard surgical treatment for operable locally advanced disease. The role of BCS is unclear and the subject of research. Previous studies demonstrating equivalence of BCS to mastectomy were performed in patients with stage I and II disease (see guideline 3 ). In the trials that compared preoperative chemotherapy with chemotherapy administered postoperatively, the proportion of women with tumours greater than $5 \mathrm{~cm}$ in diameter ranged from $5 \%$ to $27 \%$. Patients with operable stage III disease who desire to preserve their breast should be made aware that BCS is currently not a standard approach and is generally not recommended. There is a lack of evidence concerning breast reconstruction surgery in women with LABC. Reconstruction is generally performed after completion of chemotherapy and radiotherapy, because of the concern that postoperative complications could delay chemotherapy and radiotherapy.

In the largest study evaluating locoregional therapy,,$^{59,60}$ eligible patients with operable LABC had a mastectomy, 6 cycles of anthracycline-based chemotherapy and, if disease-free, were randomly assigned to receive radiotherapy or observation with radiotherapy at isolated sites of locoregional failure (Table 2). Locoregional recurrences were reduced from $24 \%$ to $15 \%$ with immediate radiotherapy (level I evidence).
Two smaller randomized trials had conflicting results regarding the value of radiotherapy. These trials are summarized in Table 2 (level I evidence) ${ }^{11}$ and Table 3 (level II evidence).$^{61}$

There is a large body of level I and level II evidence demonstrating that locoregional radiotherapy following mastectomy in patients with node-positive disease treated with systemic therapy is associated with not only a reduction in locoregional recurrence but also an increase in overall survival (see guideline on postmastectomy radiotherapy). In the 3 largest trials of postmastectomy radiotherapy, $12 \%-$ $14 \%$ of patients had stage IIIA disease. ${ }^{62-64}$ A meta-analysis of all trials in which patients were treated with systemic therapy also confirmed the benefit of locoregional radiotherapy in improving disease-free and overall survival..$^{65}$

In summary, the results of 2 randomized trials and data extrapolated from trials involving women with nodepositive disease support the use of locoregional radiotherapy in patients with LABC who are treated with mastectomy.

- Locoregional radiotherapy should be delivered to the chest wall and to the supraclavicular and axillary nodes. The role of internal mammary irradiation is unclear.

When locoregional radiotherapy is delivered following MRM for locally advanced disease, radiation should be de-

Table 4: Summary of studies comparing mastectomy with radiotherapy

\begin{tabular}{|c|c|c|c|c|c|c|}
\hline Study & Patients & $\begin{array}{l}\text { No. of } \\
\text { patients }\end{array}$ & Treatment regimens & $\begin{array}{l}\text { Duration of } \\
\text { follow-up }\end{array}$ & $\begin{array}{l}\text { Level of } \\
\text { evidence }\end{array}$ & Results/comments \\
\hline $\begin{array}{l}\text { Perloff et al } \\
(\text { CALGB study), } \\
1988^{67}\end{array}$ & $\begin{array}{l}\text { Patients with stage } \\
\text { III breast cancer } \\
\text { who received } \\
3 \text { cycles of CAFVP } \\
\text { chemotherapy and } \\
\text { whose tumour was } \\
\text { deemed operable }\end{array}$ & 87 & $\begin{array}{l}\text { 1. Mastectomy }+2 \mathrm{yr} \text { of } \\
\text { CAFVP chemotherapy } \\
\text { 2. Radiotherapy }+2 \mathrm{yr} \\
\text { of CAFVP } \\
\text { chemotherapy }\end{array}$ & Median 37 mo & II & $\begin{array}{l}\text { DFS not reported. Median survival } \\
39.3 \text { mo in mastectomy group, } \\
39.0 \text { mo in radiotherapy group } \\
\text { ( } p \text { value not reported). Local } \\
\text { recurrence } 42 \% \text { in mastectomy } \\
\text { group, } 55 \% \text { in radiotherapy group } \\
(p=0.43)\end{array}$ \\
\hline $\begin{array}{l}\text { Mourali et al, } \\
1993^{68}\end{array}$ & $\begin{array}{l}\text { Patients with rapidly } \\
\text { progressing breast } \\
\text { cancer who received } \\
3 \text { cycles of CMF } \\
\text { chemotherapy }\end{array}$ & 68 & $\begin{array}{l}\text { 1. Mastectomy }+15 \\
\text { cycles of CMF } \\
\text { chemotherapy } \\
\text { 2. } \text { Radiotherapy }+15 \\
\text { cycles of CMF } \\
\text { chemotherapy }\end{array}$ & Minimum $10 \mathrm{yr}$ & II & $\begin{array}{l}\text { DFS and OS not reported. No } \\
\text { difference in disease-free interval } \\
\text { between treatment groups } \\
\text { (percentages and } p \text { value not } \\
\text { reported) }\end{array}$ \\
\hline $\begin{array}{l}\text { De Lena et al, } \\
1981^{69}\end{array}$ & $\begin{array}{l}\text { Patients with LABC } \\
\text { who received } 3 \\
\text { cycles of AV } \\
\text { chemotherapy }\end{array}$ & 132 & $\begin{array}{l}\text { 1. Mastectomy }+7 \\
\text { cycles of AV } \\
\text { chemotherapy } \\
\text { 2. } \text { Radiotherapy }+7 \\
\text { cycles of AV } \\
\text { chemotherapy }\end{array}$ & Minimum $6 \mathrm{mo}$ & II & $\begin{array}{l}\text { DFS not reported. No difference in } \\
\text { OS (percentages and } p \text { value not } \\
\text { reported). Median duration of } \\
\text { remission } 15 \text { mo in surgical group, } \\
22 \text { mo in radiotherapy group ( } p= \\
0.58 \text { ). Total incidence of locoregional } \\
\text { recurrence } 29.6 \% \text { in surgical group, } \\
31.1 \% \text { in radiotherapy group (no } \\
p \text { value reported). Total incidence of } \\
\text { treatment failure in distant sites } 43 \% \\
\text { in surgical group, } 26.2 \% \text { in } \\
\text { radiotherapy group }(p=0.25)\end{array}$ \\
\hline
\end{tabular}

Note: $\mathrm{CALGB}=$ Cancer and Leukemia Group B, LABC = locally advanced breast cancer, $\mathrm{OS}=$ overall survival, $\mathrm{C}=$ cyclophosphamide, $\mathrm{A}=$ adriamycin, $\mathrm{F}=5$-fluorouracil $\mathrm{V}=$ vincristine, $\mathrm{P}=$ prednisone, $\mathrm{M}=$ methotrexate. 
livered to the chest wall and the supraclavicular and axillary nodes. Whether treatment to the internal mammary nodes is required is unclear. ${ }^{66}$ In many of the studies reviewed for this guideline, the internal mammary nodes were irradiated. However, there are no studies that examined the impact of such radiotherapy. It is not unreasonable to include radiotherapy to the internal mammary nodal region, provided that this can be done without treating an excessive amount of heart or lung tissue. Locoregional radiotherapy has been associated with a modest increase in late non-breast-cancer deaths of cardiac or vascular origin. ${ }^{66}$ The recommended dose of radiation is 50 Gy in 25 fractions or equivalent.

\section{Inoperable tumours}

- Patients with stage IIIB disease who respond to chemotherapy should receive surgery plus locoregional radiotherapy.

- The locoregional management of patients with stage IIIC disease who respond to chemotherapy is unclear and should be individualized.

- Patients whose disease remains inoperable following chemotherapy should receive locoregional radiotherapy with subsequent surgery, if feasible.

Three small trials compared MRM alone with locoregional radiotherapy alone following chemotherapy (Table 4). ${ }^{67-69}$ The results of these studies suggest that both treatments are equally effective after primary chemotherapy in inoperable disease (level II evidence).

No randomized trials were found that compared mastectomy plus locoregional radiotherapy with mastectomy alone following chemotherapy, but 2 case series demonstrated that locoregional control was better if both mastectomy and radiotherapy were performed ${ }^{70,71}$ (level $\mathrm{V}$ evidence).

The results of these studies and data from randomized trials in operable disease support the use of both MRM and locoregional radiotherapy in achieving optimal local control when feasible. It is unknown whether the sequence of surgery and radiotherapy makes a difference. Technical and disease factors will usually influence the order of treatments. For example, patients who have a good response to primary chemotherapy may be best managed by MRM followed by radiotherapy. Patients who remain inoperable after chemotherapy could receive radiotherapy followed by surgery, if feasible. Again, similar to operable disease, the role of BCS in this situation is unclear and is the subject of research.

The locoregional management of patients with stage IIIC disease who respond to chemotherapy is unclear. In the absence of evidence on this subgroup of patients, it is reasonable that they receive locoregional radiotherapy (including nodal irradiation). The role of completion mastectomy should be individualized and based on such factors as response to chemotherapy and radiotherapy, ab- sence of metastases on re-staging examinations and patient fitness.

Patients who are treated primarily with radiotherapy should be given tumouricidal doses to areas of bulk disease (60-66 Gy in 30 to 33 fractions or equivalent). Higher doses of radiation (70 Gy in 35 fractions by external beam or brachytherapy) to areas of bulk disease may be considered for patients if surgery is felt not to be an option and if tolerance of critical organs permits. Two case series have reported a dose-response relation with higher doses of radiation that resulted in decreased rates of local recurrence (level V evidence)..$^{72,73}$

\section{This article has been peer reviewed.}

Dr. Shenkier is with the BC Cancer Agency-Vancouver Cancer Centre and is Clinical Assistant Professor in the Department of Medicine, University of British Columbia, Vancouver, BC; Dr. Weir is with the BC Cancer Agency-Vancouver Cancer Centre and is Clinical Associate Professor in the Department of Surgery, University of British Columbia, Vancouver, BC; Dr. Levine is Professor in the Departments of Clinical Epidemiology and Biostatistics and of Medicine and is the Buffet Taylor Chair in Breast Cancer Research, McMaster University, Hamilton, Ont.; Dr. Olivotto is with the BC Cancer Agency-Vancouver Island Cancer Centre and Clinical Professor in the Department of Surgery, University of British Columbia, Victoria, BC; Dr. Whelan is with the Cancer Care Ontario Hamilton Regional Cancer Centre and is Associate Professor in the Department of Medicine, McMaster University, Hamilton, Ont.; and Dr. Reyno is with the Nova Scotia Cancer Centre, Halifax, NS (until May 1, 2003).

Competing interests: None declared for Drs. Shenkier, Weir, Levine, Olivotto and Whelan. At the time of writing the guidelines, Dr. Reyno had no competing interests; he is now an employee of Aventis Pharmaceuticals Inc.

Contributors: All of the authors were involved in reviewing the literature and categorizing the levels of evidence. They have all been involved in the writing of the many drafts of this article and all have given final approval of the version to be published.

Acknowledgements: We thank the following oncologists for their valuable advice: Dr. Vivien Bramwell, Tom Baker Cancer Centre, Calgary, Alta.; Dr. Margot Burnell, Atlantic Health Sciences Corporation, Saint John, NB; Dr. Karen Gelmon, BC Cancer Agency-Vancouver Cancer Centre, Vancouver, BC; Dr. Peter Lovrics, St. Joseph's Hospital, Hamilton, Ont.; Dr. John Mackey, Cross Cancer Institute, Edmonton, Alta.; Dr. Maureen Nolan, Nova Scotia Cancer Centre, Halifax, NS; Dr. Jean Robert, Hôpital du Saint-Sacrement, Québec, Que.; Dr. Katherine Vallis, Princess Margaret Hospital, Toronto, Ont.; and Dr. TheodoreVandenberg, London Regional Cancer Centre, London, Ont.

\section{References}

1. Singletary SE, Allred C, Ashley P, Bassett LW, Berry D, Bland KI, et al. Revision of the American Joint Committee on Cancer Staging System for Breast Cancer. 7 Clin Oncol 2002;20(17);3628-36.

2. Haagensen CD, Stout AP. Carcinoma of the breast. II: Criteria of operability. Ann Surg 1943;118:859-70, 1032-51.

3. Strom EA, McNeese MD, Fletcher GH, Romsdahl MA, Montague ED, Oswald MJ. Results of mastectomy and postoperative irradiation in the management of locoregionally advanced carcinoma of the breast. Int 7 Radiat Oncol Biol Phys 1991;21(2):319-23.

4. Toonkel LM, Fix I, Jacobson LH, Bamberg N, Wallach CB. Locally advanced breast carcinoma: results with combined regional therapy. Int 7 Radiat Oncol Biol Phys 1986;12(9):1583-7.

5. Early Breast Cancer Trialists' Collaborative Group. Polychemotherapy for early breast cancer: an overview of the randomised trials. Lancet 1998 , 352:930-42.

6. Early Breast Cancer Trialists' Collaborative Group. Tamoxifen for early breast cancer: an overview of the randomised trials. Lancet 1998;351:1451-67.

7. Therasse P, Mauriac L, Welnicka-Jaskiewicz M, Bruning P, Cufer T, Bonnefoi $\mathrm{H}$, et al. Final results of a randomized phase III trial comparing cyclophosphamide, epirubicin, and fluorouracil with a dose-intensified epirubicin and cyclophosphamide + filgrastim as neoadjuvant treatment in locally advanced breast cancer: an EORTC-NCIC-SAKK multicenter study. 7 Clin Oncol 2003;21(5):843-50.

8. Sackett DL. Rules of evidence and clinical recommendations on the use of antithrombotic agents. Chest 1989;95(Suppl):2S-4S. 
9. Brito RA, Valero V, Buzdar AU, Booser DJ, Ames F, Strom E, et al. Longterm results of combined-modality therapy for locally advanced breast cancer with ipsilateral supraclavicular metastases: the University of Texas M.D. Anderson Cancer Center experience. 7 Clin Oncol 2001;19(3):628-33.

10. Olivotto IA, Chua B, Allan SJ, Speers CH, Chia S, Ragaz J. Long-term survival of patients with supraclavicular metastases at diagnosis of breast cancer. 7 Clin Oncol 2003;21(5):851-4.

11. Klefstrom P, Grohn P, Heinonen E, Holsti L, Holsti P. Adjuvant postoperative radiotherapy, chemotherapy, and immunotherapy in stage III breast cancer. II. 5-year results and influence of levamisole. Cancer 1987;60(5):936-42.

12. Derman DP, Browde S, Kessel IL, De Moor NG, Lange M, Dansey R, et al. Adjuvant chemotherapy (CMF) for stage III breast cancer: a randomized trial. Int 7 Radiat Oncol Biol Phys 1989;17:257-61.

13. Harris JR, Lippman ME, Morrow M, Oxborne CK, editors. Diseases of the breast. 2nd ed. Philadelphia: Lippincott Williams and Wilkins; 2000.

14. Wolff AC, Davidson NE. Primary systemic therapy in operable breast cancer. 7 Clin Oncol 2000;18(7):1558-69.

15. Hortobagyi GN, Singletary SE, Strom EA. Treatment of locally advanced and inflammatory breast cancer. In: Harris JR, Lippman ME, Morrow M, Oxborne CK, editors. Diseases of the breast. 2nd ed. Philadelphia: Lippincott Williams and Wilkins; 2000. p.645-60.

16. Hortobagyi GN, Ames FC, Buzdar AU, Kau SW, McNeese MD, Paulus D, et al. Management of stage III primary breast cancer with primary chemotherapy, surgery, and radiation therapy. Cancer 1988;62(12):2507-16.

17. Fisher B, Brown A, Mamounas E, Wieand S, Robidoux A, Margolese RG, et al. Effect of preoperative chemotherapy of local-regional disease in women with operable breast cancer: findings from National Surgical Adjuvant Breast and Bowel Project B-18. 7 Clin Oncol 1997;15:2483-93.

18. Fisher B, Bryant J, Wolmark N, Mamounas E, Brown A, Fisher ER, et al. Effect of preoperative chemotherapy on the outcome of women with operable breast cancer. 7 Clin Oncol 1998;16(8):2672-85

19. Wolmark N, Wang J, Mamounas E, Bryant J, Fisher B. Preoperative chemotherapy in patients with operable breast cancer: nine-year results from National Surgical Adjuvant Breast and Bowel Project B-18. 7 Natl Cancer Inst Monogr 2001;30:96-102.

20. Van der Hage JA, van de Velde CJH, Julien JP, Tubiana-Hulin M, Vandervelden C, Duchateau L, et al. Preoperative chemotherapy in primary operable breast cancer: results from the European Organization for Research and Treatment of Cancer trial 10902. F Clin Oncol 2001;19(22):4224-37.

21. Scholl SM, Fourquet A, Asselain B, Pierga JY, Vilcoq JR, Durand JC, et al. Neoadjuvant versus adjuvant chemotherapy in premenopausal patients with tumours considered too large for breast conserving surgery: preliminary results of a randomised trial: S6. Eur 7 Cancer 1994;645-52.

22. Broët P, Scholl SM, de la Rochefordière A, Fourquet A, Moreau T, De Rycke $\mathrm{Y}$, et al. Short and long-term effects on survival in breast cancer patients treated by primary chemotherapy: an updated analysis of a randomized trial. Breast Cancer Res Treat 1999;58:151-6.

23. Mauriac L, MacGrogan G, Avril A, Durand M, Floquet A, Debled M, et al Neoadjuvant chemotherapy for operable breast carcinoma larger than $3 \mathrm{~cm}$ : a unicentre randomized trial with a 124-month median follow-up. Institut Bergonie Bordeaux Groupe Sein (IBBGS). Ann Oncol 1999;10(1):47-52.

24. Powles TJ, Hickish TF, Makris A, Ashley SE, O'Brien ME, Tidy VA, et al Randomized trial of chemoendocrine therapy started before or after surgery for treatment of primary breast cancer. 7 Clin Oncol 1995;13(3):547-52.

25. Makris A, Powles TJ, Äshley SE, Chang J, Hickish T, Tidy VA, et al. A reduction in the requirements for mastectomy in a randomized trial of neoadjuvant chemoendocrine therapy in primary breast cancer. Ann Oncol 1998; 9(11):1179-84.

26. De Placido S, Perrone F, Carlomagno C, Morabito A, Pagliarulo C, Lauria $\mathrm{R}$, et al. CMF vs alternating $\mathrm{CMF} / \mathrm{EV}$ in the adjuvant treatment of operable breast cancer. A single centre randomised clinical trial (Naples GUN-3 study). Br 7 Cancer 1995;71(6):1283-7.

27. Casper ES, Guidera CA, Bosl GJ, Hakes TB, Kaufman RJ, Shurgot B, et al Combined modality treatment of locally advanced breast cancer: adjuvant combination chemotherapy with and without doxorubicin. Breast Cancer Res Treat 1987;9:39-44.

28. Bull JM, Tormey DC, Li SH, Carbone PP, Falkson G, Blom J, et al. A randomized comparative trial of adriamycin versus methotrexate in combination drug therapy. Cancer 1978;41(5):1649-57.

29. Falkson G, Tormey DC, Carey P, Witte R, Falkson HC. Long-term survival of patients treated with combination chemotherapy for metastatic breast cancer. Eur 7 Cancer 1991;27(8):973-7.

30. Hutchins L, Green S, Ravdin P, Lew D, Martino S, Abeloff M, et al. CMF versus $\mathrm{CAF}$ with and without tamoxifen in high-risk node-negative breast cancer patients and a natural history follow-up study in low-risk node-negative patients: first results of Intergroup Trial INT 0102. Prog Proc Am Soc Clin Oncol 1998;1a.

31. Mouridsen HT, Andersen J, Andersson M, Dombernowsky P, Ejlertsen B, Rose $\mathrm{C}$, et al. Adjuvant anthracycline in breast cancer. Improved outcome in premenopausal patients following substitution of methotrexate in the CMF combination with epirubicin [abstract]. Prog Proc Am Soc Clin Oncol 1999;18:68a.
32. Levine MN, Bramwell VH, Pritchard KI, Norris BD, Shepherd LE, AbuZahra H, et al. Randomized trial of intensive cyclophosphamide, epirubicin, and fluorouracil chemotherapy compared with cyclophosphamide, methotrexate, and fluorouracil in premenopausal women with node-positive breast cancer. National Cancer Institute of Canada Clinical Trials Group. 7 Clin Oncol 1998;16(8):2651-8.

33. Fisher B, Brown AM, Dimitrov NV, Poisson R, Redmond C, Margolese RG et al. Two months of doxorubicin-cyclophosphamide with and without interval reinduction therapy compared with 6 months of cyclophosphamide, methotrexate, and fluorouracil in positive-node breast cancer patients with tamoxifen-nonresponsive tumors: results from the National Surgical Adjuvant Breast and Bowel Project B-15. F Clin Oncol 1990;8(9):1483-96.

34. French Adjuvant Study Group. Benefit of a high-dose epirubicin regimen in adjuvant chemotherapy for node-positive breast cancer patients with poor prognostic factors: 5-year follow-up results of French Adjuvant Study Group 05 randomized trial. $\mathcal{7}$ Clin Oncol 2001;19(3):602-11.

35. Fumoleau P, Kerbrat P, Romestaing P, Fargeot P, Brémond A, Namer M, et al. Randomized trial comparing six versus three cycles of epirubicin-based adjuvant chemotherapy in premenopausal, node-positive breast cancer patients: 10-year follow-up results of the French Adjuvant Study Group 01 trial. 7 Clin Oncol 2003;21:298-305.

36. Seidman AD, Reichman BS, Crown JP, Yao TJ, Currie V, Hakes TB, et al Paclitaxel as second and subsequent therapy for metastatic breast cancer: activity independent of prior anthracycline response. 7 Clin Oncol 1995;13 (5):1152-9.

37. Valero V, Holmes FA, Walters RS, Theriault RL, Esparza L, Fraschini G, et al. Phase II trial of docetaxel: a new, highly effective antineoplastic agent in the management of patients with anthracycline-resistant metastatic breast cancer. 7 Clin Oncol 1995; 13(12):2886-94.

38. Henderson IC, Berry DA, Demetri GD, Cirrincione CT, Goldstein LJ, Martino $\mathrm{S}$, et al. Improved outcomes from adding sequential paclitaxel but not from escalating doxorubicin dose in an adjuvant chemotherapy regimen for patients with node positive primary breast cancer. 7 Clin Oncol 2003;21:976-83.

39. Mamounas E, Bryant J, Lembersky BC, Fisher B, Atkins JN, Fehrenbacher L, et al. Paclitaxel following doxorubicin/cyclophosphamide as adjuvant chemotherapy for node positive breast cancer: Results from NSABP B-28 [abstract]. Prog Proc Am Soc Clin Oncol 2003;22:4.

40. Citron ML, Berry, DA, Cirrincione C, Hudis C, Winer EP, Gradishar WJ, et al. Randomized trial of dose-dense conventionally scheduled and sequential versus concurrent combination chemotherapy as postoperative adjuvant treatment of node-positive primary breast cancer: first report of Intergroup Trial C9741/Cancer and Leukemia Group B Trial 9741. 7 Clin Oncol 2003; 21:1431-9.

41. Nabholtz JM, Pienkowski T, Mackey J, Pawlicki M, Guastalla JP, Vogel C, et al. Phase III trial comparing TAC (docetaxel, doxorubicin, cyclophosphamide) with FAC (5-fluorouracil, doxorubicin, cyclophosphamide) in the adjuvant treatment of node positive breast cancer (BC) patients: interim analysis of the BCIRG 001 study [abstract]. Proc Am Soc Clin Oncol 2002; 21:36a.

42. Buzdar AU, Singletary SE, Theriault RL, Booser DJ, Valero V, Ibrahim N, et al. Prospective evaluation of paclitaxel versus combination chemotherapy with fluorouracil, doxorubicin, and cyclophosphamide as neoadjuvant therapy in patients with operable breast cancer. 7 Clin Oncol 1999;17(11):3412-17.

43. Smith IC, Heys SD, Hutcheon AW, Miller ID, Payne S, Gilbert FJ, et al. Neoadjuvant chemotherapy in breast cancer: significantly enhanced response with docetaxel. 7 Clin Oncol 2002;20(6):1456-66.

44. Heys SD, Hutcheon AW, Sarkar TK, Ogston KN, Miller ID, Payne S, et al Neoadjuvant docetaxel in breast cancer: 3 -year survival results from the $\mathrm{Ab}$ erdeen Trial. Clinical Breast Cancer 2002;3 (Suppl 2):S69-74.

45. Bear HD, Anderson S, Brown A, Smith R, Mamounas P, Fisher B, et al. The effect on tumor response of adding preoperative docetaxel to preoperative doxorubicin and cyclophosphamide: preliminary results from National Surgical Adjuvant Breast and Bowel Project protocol B-27. 7 Clin Oncol 2003, 21(22):4165-74.

46. Wood WC, Budman DR, Korzun AH, Cooper MR, Younger J, Hart RD, et al. Dose and dose intensity of adjuvant chemotherapy for stage II, node-positive breast carcinoma [published erratum appears in N Engl 7 Med 1994; 331(2):139]. N Engl 7 Med 1994;330(18):1253-9.

47. Stadtmauer EA, O'Neill A, Goldstein LJ, Crilley PA, Mangan KF, Ingle JN, et al. Conventional-dose chemotherapy compared with high-dose chemotherapy plus autologous hematopoietic stem-cell transplantation for metastatic breast cancer [comment in N Engl f Med 2000;342(15):1119-20]. N Engl f Med 2000;342(15):1069-76.

48. Peters W, Rosner G, Vredenburgh J, Sphall E, Crump M, Richardson P, et al. A prospective randomized comparison of two doses of combination alkylating agents as consolidation after CAF in high-risk primary breast cancer involving ten or more axillary lymph nodes [abstract]. Proc Am Soc Clin Oncol 1999; 18:2a.

49. Bonadonna G, Valagussa P, Brambilla C, Ferrari L, Moliterri A, Terenziani $\mathrm{M}$, et al. Primary chemotherapy in operable breast cancer: eight-year experience at the Milan Cancer Institute. 7 Clin Oncol 1998;16(1):93-100. 
50. Kuerer HM, Newman LA, Smith TL, Ames FC, Hunt KK, Dhingra K, et al. Clinical course of breast cancer patients with complete pathologic primary tumor and axillary lymph node response to doxorubicin-based neoadjuvant chemotherapy. $\tilde{f}$ Clin Oncol 1999;17(2):460-9.

51. International Breast Cancer Study Group. Duration and reintroduction of adjuvant chemotherapy for node positive breast cancer patients: an update based on 10 years follow-up. 7 Clin Oncol 1996;14:1885-94.

52. Bartelink H, Rubens RD, van der Schueren E, Sylvester R. Hormonal therapy prolongs survival in irradiated locally advanced breast cancer: a European Organization for Research and Treatment of Cancer randomized phase III trial. $\exists$ Clin Oncol 1997;15(1):207-15.

53. Albain KS, Green SJ, Ravdin PM, Cobau CD, Levine EG, Ingle JN, et al. Adjuvant chemohormonal therapy for primary breast cancer should be sequential instead of concurrent: initial results of Intergroup Trial 0100 (SWOG-8814) [abstract]. Prog Proc Am Soc Clin Oncol 2002;21:37.

54. ATAC (Arimidex, Tamoxifen Alone or in Combination) Trialists' Group. Anastrozole alone or in combination with tamoxifen versus tamoxifen alone for adjuvant treatment of postmenopausal women with early breast cancer: first results of the ATAC randomised trial. Lancet 2002;359:2131-9.

55. Winer EP, Hudis C, Burstein HJ, Chlebowski RT, Ingle JN, Edge SB, et al. American Society of Clinical Oncology technology assessment on the use of aromatase inhibitors as adjuvant therapy for women with hormone receptorpositive breast cancer: status report 2002. 7 Clin Oncol 2002;20:3317-27.

56. Alagaratnam TT, Wong J. Tamoxifen versus chemotherapy as adjuvant treatment in stage III breast cancer. Aust N Z F Surg 1986;56(1):39-41.

57. Willsher PC, Robertson JFR, Armitage NC, Morgan DAL, Nicholson RI, Blamey RW. Locally advanced breast cancer: early results of a randomized trial comparing primary treatment with tamoxifen or radiotherapy in postmenopausal women. Eur 7 Surg Oncol 1996;22(1):34-7.

58. Willsher PC, Robertson JFR, Chan SY, Jackson L, Blamey RW. Locally advanced breast cancer: early results of a randomised trial of multimodal therapy versus initial hormone therapy. Eur 7 Cancer 1997;33(1):45-9.

59. Olson JE, Neuberg D, Pandya K, Richter MP, Solin LJ, Gilchrist KW, et al The role of radiotherapy in the management of operable locally advanced breast carcinoma. Results of a randomized trial by the Eastern Cooperative Oncology Group. Cancer 1997;79(6):1138-49.

60. Fowble B. Postmastectomy radiation: a modest benefit prevails for high risk patients [editorial]. Cancer 1997;79(6):1061-6.

61. Papaioannou A, Lissaios B, Vasilaros S, Miligos S, Papadimitriou G, Kondilis $\mathrm{D}$, et al. Pre- and postoperative chemoendocrine treatment with or without postoperative radiotherapy for locally advanced breast cancer. Cancer 1983;51(7):1284-90.

62. Ragaz J, Jackson SM, Le N, Plenderleith IH, Spinelli JJ, Basco VE, et al. Adjuvant radiotherapy and chemotherapy in node-positive premenopausal women with breast cancer. N Engl 7 Med 1997;337(14):956-62 .

63. Overgaard M, Hansen PS, Overgaard J, Rose C, Andersson M, Bach F, et al. Postoperative radiotherapy in high-risk premenopausal women with breast cancer who receive adjuvant chemotherapy. N Engl 7 Med 1997;337(14):949-55.

64. Overgaard M, Jensen M-B, Overgaard J, Hansen PS, Rose C, Andersson M et al. Postoperative radiotherapy in high-risk postmenopausal breast-cancer patients given adjuvant tamoxifen: Danish Breast Cancer Cooperative Group DBCG 82c randomised trial. Lancet 1999;353:1641-8.

65. Whelan T, Julian J, Wright J, Jadad AR, Levine ML. Does locoregional radiation therapy improve survival in breast cancer? A meta-analysis. $\mathcal{f}$ Clin Oncol 2000;18(6):1220-9.

66. Recht A, Edge SB, Solin LJ, Robinson DS, Estabrook A, Fine RE, et al. Postmastectomy radiotherapy: guidelines of the American Society of Clinical Oncology. 7 Clin Oncol 2001;19:1539-69.

67. Perloff M, Lesnick GJ, Korzun A, Chu F, Holland JF, Thirlwell MP, et al Combination chemotherapy with mastectomy or radiotherapy for stage III breast carcinoma: a Cancer and Leukemia Group B study. 7 Clin Oncol 1988;6 (2):261-9.
68. Mourali N, Tabbane F, Muenz LR, Behi J, Moussa FB, Jaziri M, et al. Tenyear results utilizing chemotherapy as primary treatment in nonmetastatic, rapidly progressing breast cancer. Cancer Invest 1993;11(4):363-70.

69. De Lena M, Varini M, Zucali R, Rovini D, Viganotti G, Valagussa P, et al. Multimodal treatment for locally advanced breast cancer. Results of chemotherapy-radiotherapy versus chemotherapy-surgery. Cancer Clin Trials 1981; 4(3):229-36

70. Pierce LJ, Lippman M, Ben-Baruch N, Swain S, O’Shaughnessy J, Bader JL, et al. The effect of systemic therapy on local-regional control in locally advanced breast cancer. Int 7 Radiat Oncol Biol Phys 1992;23(5):949-60.

71. Perez CA, Fields JN, Fracasso PM, Philpott G, Soares RL, Jr, Taylor ME, et al. Management of locally advanced carcinoma of the breast . II. Inflammatory carcinoma. Cancer 1994;74(1 Suppl):466-76.

72. Arriagada R, Mouriesse H, Sarrazin D, Clark RM, Deboer G. Radiotherapy alone in breast cancer. I. Analysis of tumor parameters, tumor dose and local control. Int 7 Rad Oncol Biol Phys 1985;11:1751-7.

73. Van Limbergen E, Van der Schueren E, Van den Bogaert W, Van Wing J Local control of operable breast cancer after radiotherapy alone. Eur 7 Cancer 1990;26(6):674-9.

Correspondence to: Dr. Mark Levine, Rm. 104, Henderson Research Centre, Henderson Hospital, 711 Concession St., Hamilton ON L8V 1C3; fax 905 389-9288

\section{Members of the Steering Committee on Clinical Practice Guidelines for the Care and Treatment of Breast Cancer} Chair: Dr. Mark Levine (Cancer Care Ontario), Hamilton Regional Cancer Centre and McMaster University, Hamilton, Ont. Members: Dr. Penny Barnes, Queen Elizabeth II Health Sciences Centre, Halifax, NS; Dr. Judy Caines (Federal) Provincial/Territorial Advisory Committee on Health Services), Nova Scotia Cancer Centre, Halifax, NS; Dr. Jacques Cantin (deceased) (Royal College of Physicians and Surgeons of Canada), Centre hospitalier de l'Université de Montréal, Montréal, Que.; Dr. Beverley Carter, St. John's, Nfld.; Dr. Eva Grunfeld (College of Family Physicians of Canada), Ottawa Regional Cancer Centre, Ottawa, Ont.; Ms. Sabina Mallard (Canadian Breast Cancer Network), consumer representative, Stratford, PEI; Dr. Mohamed Mohamed (Saskatchewan Cancer Foundation), Saskatoon Cancer Centre, Saskatoon, Sask.; Dr. Ivo A. Olivotto (BC Cancer Agency), Vancouver Island Cancer Centre and University of British Columbia, Victoria, BC; Dr. Leonard Reyno (Cancer Care Nova Scotia), Nova Scotia Cancer Centre, Halifax, NS; Dr. Carol Sawka (Cancer Care Ontario), Toronto Sunnybrook Regional Cancer Centre, Toronto, Ont.; Dr. Hugh Scarth (Atlantic Health Sciences Corporation), Saint John Regional Hospital, Saint John, NB; and Dr. Timothy Whelan (Cancer Care Ontario), Hamilton Regional Cancer Centre and McMaster University, Hamilton, Ont.

A guide for patients on the treatment of locally advanced breast cancer appears on page 994 . 


\section{Appendix 1}

\section{Questions and answers on the treatment of locally advanced breast cancer}

\section{A guide for women and their physicians}

\section{What is locally advanced breast cancer?}

Patients with locally advanced breast cancer or $L A B C$ have large breast tumours (more than $5 \mathrm{~cm}$ wide) and one or more of the following:

- Tumours that are attached to the chest wall or skin, or skin that is ulcerated or red.

- Lymph nodes (sometimes called glands) in the armpit that have become attached to structures in the armpit.

- Lymph nodes above the collarbone (called supraclavicular nodes) that contain cancer cells.

These features indicate that the cancer is more extensive than earlier stage breast cancer (see guideline 3) but has not yet spread or metastasized to other parts of the body. Inflammatory breast cancer, which makes the breast red and swollen, is a type of LABC.

\section{How is LABC treated?}

The treatment of LABC is complex and must be tailored to the individual. Patients will often need a combination of therapies (called combined modality treatment), which includes:

- Chemotherapy (treatment with anticancer drugs)

- Radiotherapy (treatment with high-energy x-rays)

- A mastectomy (surgery that removes all breast tissue)

- Hormonal therapy (treatment with the drug tamoxifen)

Usually 3 cancer specialists - a surgeon, a medical oncologist and a radiation oncologist - will work together to choose and schedule the best combined modality treatment for you.

\section{What more can I learn about LABC from this guide?}

This guide summarizes a list of recommendations for treating patients with $\mathrm{LABC}$. The recommendations have been written with the use of a treatment framework based on whether or not surgery is possible for the patient with newly diagnosed LABC. In other words, is the tumour operable (it can be removed completely in an operation) or is it inoperable (it cannot be removed completely)?

Inoperable tumours are either:

- attached to the chest wall or skin, or

- inflammatory, or

- have lymph nodes attached to structures in the armpit, or have spread to a lymph node above the collarbone.

\section{I have an operable tumour...}

Will I be offered chemotherapy?

Yes, you will probably be offered chemotherapy unless your general health indicates that you would not tolerate it well. In general, the chemotherapy should include anthracyclines (anticancer agents such as doxorubicin and epirubicin). You will most likely have 6 months of chemotherapy (see guideline 8) - scheduled in 1 of 2 ways:

- Anticancer drugs will be given before surgery to shrink the tumour and make surgery easier, or

- Surgery will be done first and then anticancer drugs will be given to try to destroy any remaining cancer cells.

You will need to discuss with your doctor which approach will be used. You will also need to see if your health and level of fitness allow you to have chemotherapy.

\section{Will I be offered radiotherapy?}

Yes, you will probably be offered radiotherapy. This is usually scheduled after surgery and chemotherapy. The radiation will be directed at your chest wall and at the lymph nodes in your armpit and above your collarbone.

\section{Will I be offered hormonal therapy?}

Yes, if you have a tumour that is identified as one that is likely to respond to hormones. In that case, your doctor will probably recommend that you take tamoxifen (a drug that blocks the effect of estrogens) for 5 years after you finish the chemotherapy and radiotherapy, to decrease the chance of the cancer returning. Women who may not tolerate chemotherapy may be offered tamoxifen instead.

\section{I have an inoperable tumour... Will I be offered chemotherapy?}

Yes, you will probably be offered chemotherapy that includes anthracyclines (anticancer agents such as doxorubicin and epirubicin). If anthracyline-based chemotherapy does not help, you may then be offered taxane-based chemotherapy (anticancer agents such as paclitaxel and docetaxel). If your cancer responds well to a particular kind of chemotherapy, you will have 4 to 6 months of treatment (see guideline 8 ). The way your cancer responds to the anticancer drugs will determine what treatment you receive next. For example, if the anticancer drugs make the tumour disappear, you may be offered surgery before radiotherapy. If the anticancer drugs have less effect, your physician will probably suggest radiotherapy before considering surgery. Your medical specialists will also need to consider other treatment options if your health and level of fitness do not allow you to have chemotherapy.

\section{Will I be offered radiotherapy?}

Yes, you will probably be offered radiotherapy. If your cancer responds to chemotherapy, you may be offered surgery with radiotherapy to follow. If your cancer responds less well to chemotherapy or you are not able to have chemotherapy, you will probably be offered radiotherapy first. At whatever point you receive radiotherapy, the radiation will be directed at your chest wall and at the lymph nodes in your armpit and above your collarbone.

\section{Will I be offered hormonal therapy?}

Yes, if you have a tumour that is identified as one that is likely to respond to hormones. In that case, your doctor will probably recommend that you take tamoxifen (a drug that blocks the effect of estrogens) for 5 years after you finish the chemotherapy and radiotherapy, to decrease the chance of the cancer returning. Women who may not tolerate chemotherapy may be offered tamoxifen instead. 